\title{
A Study of Perceived Stress \& Coping in Interns in a Tertiary Care Hospital in a North Eastern State of India
}

\author{
Amit Nagdive ${ }^{1}$, R.U. Zaman², Himanshu Deepak Mansharamani ${ }^{3}$ Prakash B. Behere ${ }^{4}$, Rouchelle Fernandes ${ }^{5}$ \\ ${ }^{1}$ Department of Psychiatry, Jawaharlal Nehru Medical College, Datta Meghe Institute of Medical \\ Sciences (Deemed to Be University), Sawangi, Wardha, Maharashtra, India. ${ }^{2}$ Department of \\ Psychiatry, Slichar Medical College, Assam, India. ${ }^{3}$ Department of Psychiatry, Vishesh Hospital, \\ Indore, Madhya Pradesh, India. ${ }^{4}$ Department of Psychiatry, Jawaharlal Nehru Medical College, \\ Director School of Advanced Studies, Datta Meghe Institute of Medical Sciences (Deemed to Be \\ University), Sawangi, Wardha, Maharashtra, India. ${ }^{5}$ Department of Psychiatry, Jawaharlal Nehru \\ Medical College, Datta Meghe Institute of Medical Sciences (Deemed to Be University), Sawangi, \\ Wardha, Maharashtra, India.
}

\section{ABSTRACT}

\section{BACKGROUND}

Internship is a year of tremendous change both personally \& professionally. The stress of internship stems from academic pressure, perfectionist standard and demanding nature of medical practice which requires involvement with most personal or emotionally draining aspects of life (human suffering, death, sexuality and fear). We wanted to study the stressful life events in the intern population, coping strategies adopted by the study group, co-relation between perceived stressful life event and coping in study group, and the socio-demographic variables and its corelation with perceived stress and coping in study group.

\section{METHODS}

The study was carried out in the Department of Psychiatry of a Tertiary Health Care Centre in a North Eastern State of India for a period of one year. 100 interns were included in the study. General Health Questionnaire-30, The Perceived Stress Scale, Presumptive Stressful Life Event Scale, Ways Of Coping Questionnaire (WOCQ) were used to assess stress and coping in in the subjects. Statistical Analysis was done using SPSS version 16, Spearman's Rank correlation test and Man Whitney U test.

\section{RESULTS}

Within the study group, females have more perceived stress, as compared to males. Urban population has more stressful life events \& perceived stress as compared to rural \& semi-urban. Positive reappraisal is most common coping mechanism used by study group followed by self-controlling \& escape avoidance. Stressful life events have better co-relation to coping styles as compared to perceived stress.

\section{CONCLUSIONS}

Interns experience significant stress which has considerable impact on coping mechanisms.

\section{KEY WORDS}

Stress, Interns, Coping, Tertiary Care
Corresponding Author:

Dr. Himanshu Deepak Mansharamani,

Department of Psychiatry,

Vishesh Hospital, Indore-452001,

Madhya Pradesh, India.

E-mail: himanshu.mansha@gmail.com

DOI: $10.14260 / \mathrm{jemds} / 2020 / 864$

How to Cite This Article:

Nagdive A, Zaman RU, Mansharamani HD, et al. A study of perceived stress \& coping in interns in a tertiary care hospital in a North Eastern state of India.J Evolution Med Dent Sci 2020;9(52):3950-3955, DOI: $10.14260 / j e m d s / 2020 / 864$

Submission 14-08-2020,

Peer Review 04-11-2020,

Acceptance 11-11-2020,

Published 28-12-2020.

Copyright (c) 2020 JEMDS. This is an open access article distributed under Creative Commons Attribution License [Attribution 4.0 International (CC BY 4.0)] 


\section{BACKGROUND}

This may be true theoretically that $4 \frac{1}{2}$ years long course of MBBS is sufficient to train naïve, young mind to understand illnesses and diseases. But, in reality managing discomfort and symptoms of real patients is different. Mere knowledge about human body is and its diseases is not enough for a medical student. Other things like communication and clinical skills, confidence, moral ethics and abundant common sense is also required for which a medical student gets only one year out of $5 \frac{1}{2}$ year medical course - the internship. ${ }^{1}$

A tremendous change can be seen both personally and professionally during the year of internship. ${ }^{2}$ Issues like sleep deprivation, relocation, financial issues, reduced time with friends and family and demands of patient care can challenge the capacity of adaptation of interns. It is a well-known fact that medical education is stressful and can be physically and emotionally demanding. As medical interns have a busy and demanding schedule stress is prevalent among them too. ${ }^{3,4} \mathrm{~A}$ potential source of stress other than factors like exhausting work hours, continuous evaluation process, striving for higher grades, goals etc. is the stress to get selected in P.G. entrance exams, and interns get a limited time period to cover the enormous syllabus for the exam. ${ }^{5}$

Unique academic challenges like illness, disease, dying etc., which are emotionally challenging are faced by a medical student, which makes them more vulnerable to stress and anxiety than students in other academic courses. ${ }^{6}$ In medical students, stress has been co-related with sleep patterns, negative mood states, exercise habits and low self-esteem. It has also been associated with developmental demands of young adulthood including parental conflicts, relationships and financial issues. ${ }^{7}$ Other causes of distress in intern students could be, personal factors such as life events, coping strategies, relationship issues, substance abuse, poor self-care etc. and professional factors such as workload, exposure to death / suffering, student loan debt, ethical conflicts, institutional culture etc. ${ }^{8}$ Keeping in view the high degree of stress in interns and the paucity of study literature in Indian setting context, this study attempts at assessing the perceived stress and also the coping strategies adopted by this special population.

\section{Objectives}

- To assess the stressful life events in medical interns.

- To assess coping strategies adopted by study group.

- To find out the co-relation between perceived stressful life event and coping in study group.

- To find out sociodemographic variables and its association with perceived stress and coping in study group.

\section{METHODS}

This cross-sectional study was carried out for a duration of one year from August 2011 to July 2012, at Department of Psychiatry of a Tertiary Health Care Centre in a North Eastern State of India. The study received the ethical approval from the Institutional Review Board. From every participant a written consent was obtained, and they were free to withdraw the consent at any point of time, without affecting their further progress.

\section{Sample}

There were 150 interns in a batch, posted for 15 days in Department of Psychiatry by rotation. The subjects of the study were interns posted in Department of Psychiatry, at a medical college and tertiary care hospital in North-East India. The interns fulfilling the inclusion criteria for the study and those giving a written consent were included in the study. The sample size was 100 .

\section{Inclusion Criteria}

- Interns of both sexes, who had completed at-least 6 months of internship period.

- Who provided written consent

- Had GHQ (General Health Questionnaire) score less than 50 , and

- Understood Hindi or English.

\section{Exclusion Criteria}

- Interns with co-morbid psychiatric disorders.

- Who had completed less than 6 months in internship.

- Who didn't provide written consent, and

- Had GHQ score more than 50.

\section{Tools Used}

\section{Semi-Structured Proforma}

For assessment of socio-demographic variables.

\section{General Health Questionnaire-30 (GHQ-30)}

First designed by Goldberg ${ }^{9}$ in 1972 . It is a screening test which can be self-administered and the aim is to detect psychiatric disorders. It can be used in community settings by a primary health care worker too. The GHQ has two main uses, when illness is seen as a category: to estimate the prevalence of illness in a particular population; as a means of picking up cases of 'hidden psychiatric illnesses' in general medical clinics. GHQ-30 has a specificity of $87.0 \%$ and sensitivity of $91.4 \%$.

\section{The Perceived Stress Scale (Sheldon Cohen 1983)10}

It is a self-report questionnaire which consists of 14 -items. It measures persons' evaluation of stressfulness of the situations in past month of their lives. The items are easy to understand and responses alternatives are easy to grasp, but for selfadministration the person should be at least a junior high school pass out. Each item score has a range of 0 to 4 and the total score may vary from 0 - 56 .

\section{Presumptive Stressful Life Event Scale (PSLES) ${ }^{11}$}

Life events are defined as discrete experiences that disrupt an individual's usual activities, causing a substantial change and readjustment. Examples include illness or injury, marriage, divorce and loosing or changing a job. In the literature on stress, life events have been traditionally considered as one type of stressor, along with chronic strains (ongoing stressful 
circumstances such as living with disability or poverty). PSLES consist of 51 items was applied to measure stress due to life events. The scale is standardized for two time frames - life time and one year. The scale is easy to administer and assessment is done by marking whether a life event is present or not and scoring is done by simply adding the assigning the score on the specified items. The maximum score of stress is given to death of spouse (95) and pleasure trip as the lowest.

\section{Ways of Coping Questionnaire (WOCQ) (Susan Folkman and Richard S. Lazarus, 1980) ${ }^{12}$}

It assesses the coping process, not coping deposition or style. The questionnaire has 66 questions in total and measures 8 types of coping strategies, which are: distancing, confrontive coping, planful problem solving, self-controlling, accepting responsibility, escape avoidance, seeking social support and positive reappraisal.

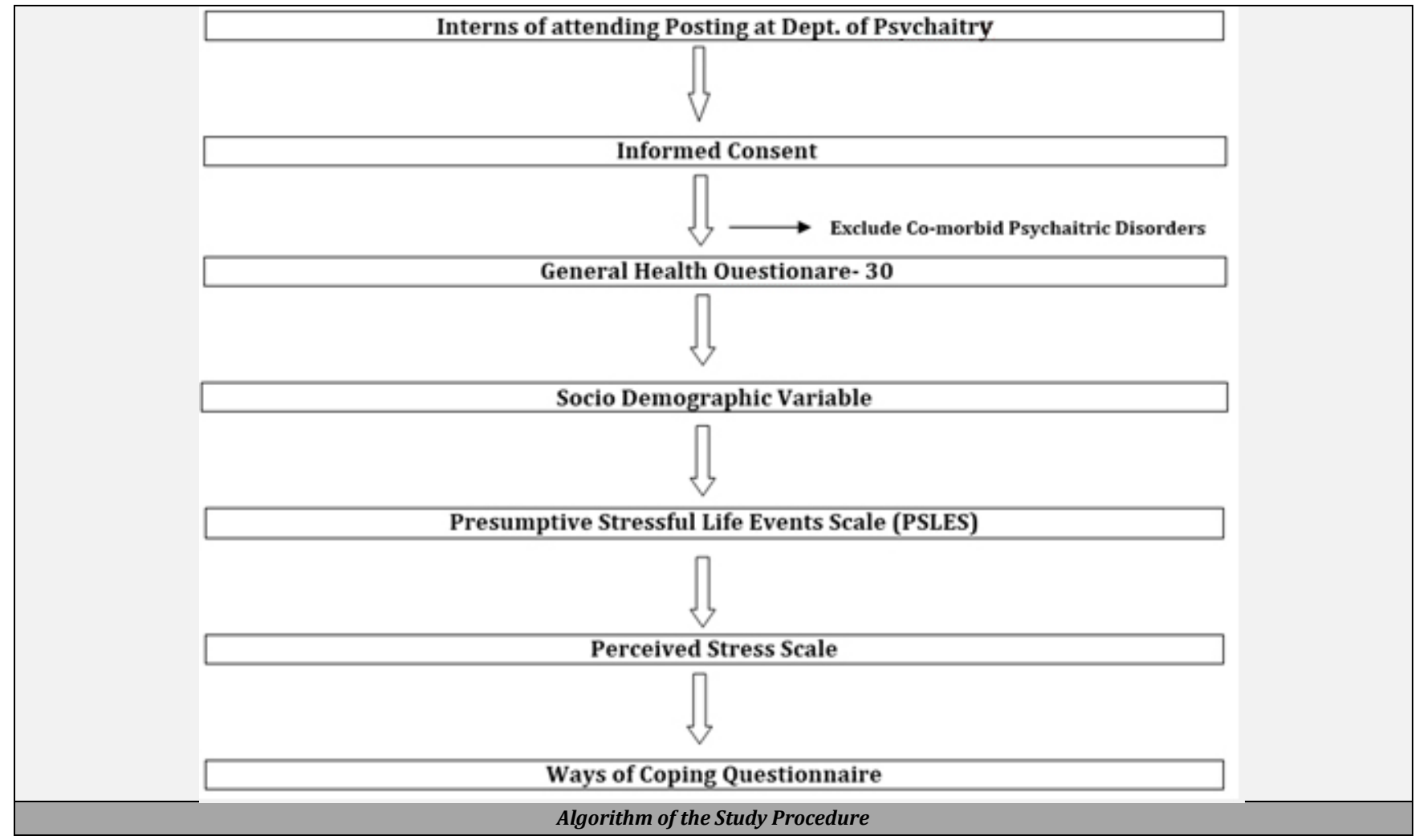

\section{Statistical Analysis}

The information collected was analysed using Statistical Package for Social Science version 16 (SPSS-16). Spearman's Rank correlation test was used to assess degree of association between variables of multiple factors. Man Whitney U test was used for comparisons of means and $\mathrm{P}$ value was considered significant at $5 \%$ i.e. $(\mathrm{p}<0.05)$.

\section{RESULTS}

A total of 100 interns were included in the study out of which 57 were males and 43 were females. Life event scores of both male as well as female were significant, but in case of perceived stress scores, females were found to be significant, not the males. Both males and females were similar in coping styles with positive reappraisal being the predominant coping used by both the groups. The difference in life event score for all three types of families i.e., joint, nuclear and extended were found to be statistically significant whereas perceived stress scores were seen to be significant only in case of nuclear and extended families. Positive reappraisal was found to be the predominant coping style in joint and nuclear families, whereas in case of extended families self-controlling was found to be predominant coping style.
Statistically significant difference was found between life events in Hindus and Muslims. The Muslims scored higher as compared to Hindus. In perceived stress the difference was statistically significant in all religions, highest was in Christians, then Hindus \& Muslims had lowest score.

Marital status was found to be statistically significant in all three categories for both life events as well as perceived stress. In case of predominant coping mechanisms used, both married and unmarried had positive reappraisal as predominant coping mechanism, while self-control was found to be predominant coping mechanism in case of others.

Life events scores and perceived stress scores was found to be most significant in case of urban population, which is followed by semi-urban and rural population in that order. In case of predominant coping mechanisms, self-controlling was found to be most common among rural and semi-urban, whereas, positive reappraisal was found to be most common in case of urban population among the study group.

2 to 5 was found to be most significant number of perceived stressful life events followed by $<2$ in both males and females within the study group. $>5$ number of perceived stressful life events were not found to be significant.

While comparing life event scores with perceived stress scores, it was seen that they were strongly correlated in case of life events no. 2 to 5 , which is followed by $>5$ and life events no. $<2$ in order. A very good amount of degree of association 
was observed in all three cases. (Table 1)

\begin{tabular}{|cccc|}
\hline $\begin{array}{c}\text { Number of Perceived } \\
\text { Stressful Life Events }\end{array}$ & $\begin{array}{c}\text { Life Event } \\
\text { Score }\end{array}$ & $\begin{array}{c}\text { Perceived Stress } \\
\text { Score }\end{array}$ & Correlation \\
\hline 2 & 17.25 & 22.17 & 0.6101 \\
2 to 5 & 136.31 & 22.81 & 0.8732 \\
$>5$ & 386.88 & 26.41 & 0.7645 \\
\hline Table 1. Distribution of Life Event Score and Perceived Stress Score \\
\hline
\end{tabular}

Coping mechanism positive reappraisal was found to be most significant both in case of males and females, and this was followed by self-controlling, escape avoidance, and seeking social support in order. Other coping mechanisms (i.e., distancing, planful problem solving and confrontive coping) are not observed to be significant. Accepting responsibility was not found to be predominant coping mechanism of any person in study group. (Table 2).

\begin{tabular}{|c|c|c|c|c|}
\hline \multirow{2}{*}{ Coping Mechanism } & \multicolumn{4}{|c|}{ Number of Subjects } \\
\hline & Males & P-Value & Females & P-Value \\
\hline Positive Reappraisal & 18 & $0.003^{*}$ & 21 & $0.001^{*}$ \\
\hline Self-Controlling & 12 & $0.004^{*}$ & 10 & $0.005^{*}$ \\
\hline Distancing & 3 & 0.346 & 5 & 0.32 \\
\hline Escape Avoidance & 13 & $0.0061^{*}$ & 3 & $0.0057^{*}$ \\
\hline Seeking Social Support & 4 & $0.0064^{*}$ & 3 & $0.0067^{*}$ \\
\hline Confrontive Coping & 1 & 0.58 & 1 & 0.63 \\
\hline Planful Problem Solving & 6 & 0.47 & - & - \\
\hline \multicolumn{5}{|c|}{ Table 2. Distribution of Coping in the Study Group } \\
\hline
\end{tabular}

\begin{tabular}{|c|c|c|c|c|}
\hline \multirow[b]{2}{*}{ Coping Mechanism } & \multicolumn{4}{|c|}{ Perceived Stress Scores (Mean) } \\
\hline & Males & $\begin{array}{c}\text { Factor } \\
\text { Loading }\end{array}$ & Females & $\begin{array}{c}\text { Factor } \\
\text { Loading }\end{array}$ \\
\hline Positive Reappraisal & 20.944 & 0.876 & 24.190 & 0.932 \\
\hline Self-Controlling & 23 & 0.916 & 23.4 & 0.886 \\
\hline Distancing & 23 & 0.867 & 22.8 & 0.766 \\
\hline Escape Avoidance & 23.15 & 0.784 & 37.33 & 0.843 \\
\hline Seeking Social Support & 25.25 & 0.862 & 22.33 & 0.722 \\
\hline Confrontive Coping & 25 & 0.694 & 14 & 0.603 \\
\hline Planful Problem Solving & 21.66 & 0.586 & - & - \\
\hline
\end{tabular}

From the factor analysis of correlation study, it is seen that the coping mechanisms were strongly correlated with perceived stress. In case of male, the factor loading ranges from 0.586 to 0.916 and in case of females it ranges 0.603 to 0.932. (Table 3). Coping Mechanisms are found to be strongly correlated with life events, with a factor loading of 0.638 to 0.832 for males and 0.528 to 0.866 for females. (Table 4)

\begin{tabular}{|ccccc|}
\hline $\begin{array}{c}\text { Coping } \\
\text { Mechanism }\end{array}$ & Males & $\begin{array}{c}\text { Life Event Scores } \\
\text { Factor } \\
\text { Loading }\end{array}$ & Females & $\begin{array}{c}\text { Factor } \\
\text { Loading }\end{array}$ \\
Positive Reappraisal & 169.98 & 0.783 & 121.47 & 0.765 \\
Self-controlling & 155.58 & 0.638 & 115 & 0.692 \\
Distancing & 91.33 & 0.577 & 102.2 & 0.528 \\
Escape Avoidance & 147.84 & 0.832 & 228.66 & 0.866 \\
Seeking Social Support & 164 & 0.788 & 77.66 & 0.793 \\
Confrontive Coping & 157 & 0.774 & 84 & 0.697 \\
Planful Problem Solving & 303 & 0.686 & - & - \\
\hline Table 4. Correlation of Coping Mechanisms and Mean Life Event Scores \\
\hline
\end{tabular}

Coping styles in respect of life events and perceived stress showed positive correlation in case of life events with a factor loading of 0.754 to 0.934 and in perceived stress with a factor loading of 0.579 to 0.746 . Comparing these two, it was seen that life events are more closely related with coping styles in comparison to perceived stress. (Table 5).

\begin{tabular}{|ccccc|}
\hline Coping Mechanism & $\begin{array}{c}\text { Life- } \\
\text { Events }\end{array}$ & $\begin{array}{c}\text { Factor } \\
\text { Loading }\end{array}$ & $\begin{array}{c}\text { Perceived } \\
\text { Stress }\end{array}$ & $\begin{array}{c}\text { Factor } \\
\text { Loading }\end{array}$ \\
\hline Positive Reappraisal & 143.82 & 0.841 & 22.692 & 0.632 \\
Self-Controlling & 137.13 & 0.783 & 23.1818 & 0.602 \\
Distancing & 98.125 & 0.754 & 22.875 & 0.591 \\
Escape Avoidance & 163 & 0.934 & 25.81 & 0.746 \\
Seeking Social Support & 127 & 0.833 & 24 & 0.722 \\
Confrontive Coping & 120.5 & 0.844 & 19.5 & 0.579 \\
Planful Problem Solving & 303 & 0.902 & 21.66 & 0.631 \\
\hline Table 5. Correlation of Life Events, Perceived Stress \\
and Coping in the Study Group \\
\hline \multicolumn{5}{|c}{} \\
\hline
\end{tabular}

\section{DISCUSSION}

The present study was a sincere attempt to evaluate the life event related stress, perceived stress and coping style in Interns of a tertiary care hospital in North East India. The study was carried out at the Department of Psychiatry, within a period of one year. The study samples were drawn from the Interns attending the Department for completion of mandatory rotating internship. At the end of one year, 100 interns were included in the study. Data relating to the demographic parameters were obtained through a semi structured proforma, GHQ-30, stressful life events, perceived stress, and coping styles were obtained through self-rated scales.

\section{Demographic Features}

The study group had similar education, income and age group ranging from 22 years to 26 years. Within the study group, females experienced higher amount of perceived stress as compared to males, which is similar to findings by Tyssen $\mathrm{R}$ et $\mathrm{al},{ }^{13}$ but were found to be different from findings of Gavin $\mathrm{R}$ Sun et al ${ }^{14}$ Kari Kjeldstadli et al ${ }^{15}$ and Supe et al, ${ }^{16}$ who reported no sex differences among perceived stress. Also, findings of present study contradict with findings of Stucky et al ${ }^{17}$ which found that males have more perceived stress than females during internship.

With respect to Coping Strategies, present study found no difference between predominant coping styles among males and females, which is similar to findings of Stern M etal. ${ }^{18}$ With respect to type of families, life event score for all three types of families were found to be significant, whereas, perceived stress scores are seen significant only in case of nuclear and extended families respectively. Predominant coping mechanism of joint and nuclear families was positive reappraisal, and in case of extended families it was found to be self-controlling.

Both Perceived stress as well as Life events is found to be less in case of married, as compared to unmarried and others. Our findings are in concordance with the findings of Kelner $M$ et $\mathrm{al}^{18}$ who found that marital status is associated with lower stress, but was found to be in dis-concordance with Gavin $\mathrm{R}$ Sun et al, ${ }^{14}$ who found no effect of marital status on difference in stress levels. Predominant coping mechanism in case of both married and unmarried was found to be positive reappraisal, whereas, in case of others, it was found to be self-controlling.

In case of domicile, Perceived stress was found to be less in case of rural population, as compared to, urban and semiurban population. 


\section{Distribution of Stressful Life Events in the Study Group}

Both males and females had 2 - 5 stressful life events during their internship period, followed by $<2$ and $>5$ respectively. In case of both males and females, most common number of Stressful Life Events was found to be 2 to 5, followed by, $<2$, and $>5$ respectively, out of which, number of events 2 to 5 and $<2$ were found to be statistically significant.

\section{Correlation of Life Events and Perceived Stress in the Study Group}

In the present study, while comparing Life events and Perceived stress, it is seen that they are strongly correlated (Pearson's correlation co-efficient ranging from 0.6101 to 0.8732) in case of number of life events. As the number of Life events increases, perceived stress also increases among the study group, which is also supported by findings of Liselotte $\mathrm{N}$. Dyrbyeet $\mathrm{al}^{8}$ who found that number of Life Events correlated with burnout.

\section{Distribution of Coping Mechanisms in the Study Group}

In the present study, coping mechanism positive reappraisal, is found to be most significant between both males as well as females, followed by self-controlling, escape avoidance and seeking social support. Other coping mechanisms, i.e., distancing, planful problem solving, and confrontive coping are not observed to be statistically significant. These findings were contradictory to those of Sami AbdoRadman Al-Dubai et ${\mathrm{al},{ }^{19}}^{19}$ Albert Wu et $\mathrm{al}^{20}$ and similar to those of Stern Met et al ${ }^{18}$ who found no sex differences in coping responses.

\section{Correlation of Coping Mechanism and} Perceived Stress in the Study Group

In the present study, it is seen that, Coping Mechanisms are strongly correlated to perceived stress as found from factor analysis. In case of males, factor loading ranges from 0.586 to 0.916 and in case of females it ranges from 0.603 to 0.932 . These findings are similar to that of Sami AbdoRadman AlDubai et al, ${ }^{19}$ AN Supe et al $^{16}$ who found significant association between Perceived Stress and Coping. In case of males having higher Perceived Stress, most common coping mechanism was seeking social support, followed by confrontive coping, distancing and escape avoidance, while in case of females, those having higher perceived stress, most common coping mechanism was escape avoidance, followed by, positive reappraisal and self-controlling. These findings are contradictory to that of AN Supe et al, ${ }^{16}$ who found higher Stress in persons using positive reappraisal, accepting responsibility and planful problem solving, and Sami AbdoRadman Al-Dubai et $\mathrm{al}^{19}$ who found higher stress associated with denial, venting, distancing.

\section{Correlation of Coping Mechanism and Life Events in the Study Group}

In the present study, it is seen that, Coping Mechanisms are strongly correlated to life events, with factor loading ranging from 0.638 to 0.832 in males and 0.528 to 0.866 in case of females. In the study group, males having higher Life events, most common Coping Mechanism was Positive Reappraisal followed by, seeking social support, self-controlling and confrontive coping, while, in females having higher life events, most common coping mechanism was, escape avoidance, followed by positive reappraisal, self-controlling and distancing.

\section{Correlation of Perceived Stress, Life Events} and Coping Mechanism in the Study Group

In the present study, so far Coping mechanisms in respect of Perceived Stress and Life Events were considered, a strong positive correlation was seen in life events with a factor loading of 0.754 to 0.934 and in case of perceived stress with a factor loading of 0.579 to 0.746 . Comparing these two, it was seen that, as far as coping mechanisms were considered, Life events were more closely related to coping mechanisms, in comparison to perceived stress.

\section{CONCLUSIONS}

Females were associated with higher stress whereas, males, being married, belonging to rural background, joint family were associated with lower perceived stress during internship. Perceived stress was significantly impacted by number of life events experienced by an individual. Coping mechanisms used by any individual had significant correlation with life events and perceived stress experienced by interns. Out of the two, life events had significantly more impact on coping mechanisms used as compared to perceived stress. Few studies are available which are done in the Indian context and further studies are required to formulate appropriate strategies.

\section{Limitations}

This study does not compare stress experienced by study group with that of controls. The use of self-reporting questionnaire may lead to bias. The study lacks follow-up and involves one time cross-sectional assessment only.

Data sharing statement provided by the authors is available with the full text of this article at jemds.com.

Financial or other competing interests: None.

Disclosure forms provided by the authors are available with the full text of this article at jemds.com.

\section{REFERENCES}

[1] Dhungana V, Sthapit B. Internship: learning to be a doctor. Kathmandu University Medical Journal 2009;7(28):3413.

[2] Bellicini LM, Baine M, Shea JA. Variation of mood and empathy during internship. JAMA 2002;287(23):31-44.

[3] Panchu P, Ali SL, Thomas T. The inter-relationship of personality with stress in medical students. International Journal of Clinical and Experimental Physiology 2016;3(3):134-9. 
[4] Ray I, Joseph D. Stress in Medical Students. JK Science 2010;12(4):163-4.

[5] Vinothkumar M, Arathi A, Joseph $M$, et al. Coping, perceived stress and job satisfaction among medical interns: the mediating effect of mindfulness. Ind Psychiatry J 2016;25(2):195-201.

[6] Elzubeir MA, Elzubeir KE, Magzoub ME. Stress and coping strategies among Arab medical students: towards a research agenda. Educ Health (Abingdon) 2010;23(1):355.

[7] Spegman AM. Herin S. Chiropractic interns perceptions of stress and confidence. J Chiropr Educ 2007;21(2):129-37.

[8] Dyrbye LN, Thomas MR, Shanafelt TD. Medical student distress: causes, consequences and proposed solutions. Mayo Clin Proc 2005;80(12):1613-22.

[9] Goldberg DP. The detection of psychiatric illness by questionnaire; a technique for the identification and assessment of non-psychotic psychiatric illness. Oxford University Press 1972.

[10] Cohen S, Kamarck T, Mermelstein R. A global measure of perceived stress. J Health Soc Behav 1983;24(4):385-96.

[11] Singh G, Kaur D, Kaur H. Presumptive stressful life events scale (psles) - a new stressful life events scale for use in India. Indian J Psychiatry 1984;26(2):107-14

[12] Folkman S, Lazarus RS. Manual for the ways of coping questionnaire. Consulting Psychologists Press 1988.
[13] Tyssen R, Vaglum P, Grønvold NT, et al. The relative importance of individual and organizational factors for the prevention of job stress during internship: a nationwide and prospective study. Med Teach 2005;27(8):726-31.

[14] Sun GR, Salojee H, Jansen M, et al. Dianne manning; stress during internship at three Johannesburg hospitals. South African Medical J 2008;98(1):33-5.

[15] Kjeldstadli K, Tyssen R, Finset A, et al. Life satisfaction and resilience in medical school--a six-year longitudinal, nationwide and comparative study. BMC Med Educ 2006;6:48.

[16] Supe AN. A study of stress in medical students at Seth G.S. Medical College. J Postgrad Med 1998;44(1):1-6.

[17] Stucky ER, Dresselhaus TR, Dollarhide A, et al. Intern to attending: assessing stress among physicians. Acad Med 2009;84(2):251-7.

[18] Stern M, Norman S, Komm C. Medical students' differential use of coping strategies as a function of stressor type, year of training and gender. Behav Med 1993;18(4):173-80.

[19] Al-Dubai SAR, Al-Naggar RA, Alshagga MA, et al. Stress and coping strategies of students in a medical faculty in Malaysia. Malays J Med Sci 2011;18(3):57-64.

[20] Wu AW, Folkman S, McPhee SJ, et al. How house officers cope with their mistakes. West J Med 1993;159(5):565-9. 